ter-irritation by moxæ at the base, afforded, tend strongly to strengthen this opinion. The spasmodic paroxysms in this case more nearly resembled those experienced in hydrophobia (though they were not so general as in that disease) than in any other I have ever witnessed.

CAsE 3.-Samuel Barton, æet. 36 , who had been working in a stocking-frame, four monthsago experienced an aching uneasiness about the left sterno-cleido-mastoideus muscles, speedily followed by spasmodic contractions; there was no uneasy sensation about the head; the appetite was good, and he had no symptom of indigestion, with the exception of a slightly furred tongue ; pulse feeble, not frequent; his general appearance was unhealthy. To have a moxa applied to the back of the neck; the hair to be cut close; cold shower bathing every morning. Cap. pil coloc. co. gr. x. o. n. Cap. ferri subcarb. $3 \mathrm{ij}$ ter die.

June 22. He was admitted this day into the hospital. The spasms are rather less than at the last report, which should have been dated June 8th. He has taken cold; slight inflammation in the right eye. App. emp. lytta auribus. Shave the head. Pur'sing draughtimmediately. Repeat moxa.

July 1. He has had four moxa applied since the last report. The spasms are rather less; the chin continues draxn towards the right shoulder; the tongue is white; the bowels are regular, the appetite is good, the eye is rell; no imperfection of vision, but he is rather deaf in the right ear ; this deafness, however, existed long before the access of the present complaint. He has great aching and uneasiness in the left sterno-mastoid muscle. Cont. Ferri Sub., pil. aper. ut primo prascript.

6. Has singing in the ears, spasms continue. Apply a blister from one mastoid process to the other. Apply to the shaved head, a painting of the tincture of iodine three times a day.

9. Sipanodic contractions the same; no hradach or noise in the ears, less deafiness. cont. remed.

11. The spasms are much worse, from no appreciable cause; he has no other uneasy sensations whaterer. Acupuncturation with six needles to the part afreoter. Feryat usu medicam.

16. The liead to-day is neary straight; no spasms, excepting when waking; the herd then jerks towards the right side; this is unattended with pain. Repeat the acur punctuation. He has a slight noise in the head; he is consequently requested to repeat the large blister.

23. He has had no further uneasiness in the head, since the blister, but the spasms have become again worse. Is ordered to have a stream of cold water directed upon the sterno-cleido-mastoid muscle.
27. The spasms are rather better, the ap. petite is very good; the general health is improved.

August 1. Spasms same as at last report; he has been electrified, and had croton oil applied to the mastoid region : has continued his medicine. Finding his health good, and little inconvenience from the muscular contractions, which still continued, he left the hospital at his own request, to try the effects of country air and exercise.

The nervus accessorius in its passage through the sterno-cleido-mastoideus, transmits but fer filaments to that muscle, but is almost wholly distributed to the trapezius, in consequence of which it may be reasonably doubted whether that nerve was the source of the spasm of the sterno-mastoid in this case. In consequence of this uncertainty, I did not recommend the division of the nervus accessorius, which $I$ otherwise should liave done, and certainly shall do, if another such case presents itself to my observation. As neither the brain, the stomach, nor any other viscus was disordered, and as the sterno-cleido-mastoidens is supplied by nerves which are derived from the upper portion of the spinal marrow, it may be inferred that the primary source of irritation was there situated.

Nottingham, Sep. 10th, 1836.

\section{HYDRIODATE OF POTASH.}

\section{To the Editor of THE LANCET.}

SIR:-The publication of the following case, treated with the Hydriodate of Potash, in your valnable foumal, will oblige yours, very respectfully, IAnes Roway, M.R.C.S.L. Scarborough, sept. 8, 1836 .

In June last I was called to visit William Brown, a sailor, whom I found much debilitated, having a lare node on the left tibia, below the insertion of the ligamentum patelle, the left an:le much swollen with excruciatis? pain, both in that part and in the node. Large ulcers extended along the crest of the tibia, on each leg, discharging much unhealthy matter. The man also complained of severe nocturnal pains in his limbs and head, which deprived him of pest. Fir informed me that at about the brginning of Sept. 1835, he ras seized with a violent yain in his left knee, when he ap. plied to a medical gentleman in town, who (he told me) considered the disfase to be rhemmatism, and treated him with calomel, bleeding, hot baths, Bc., without affording him any relief. Whis treatment he continued during the month of September, when his medical attendant discontinued his risits. Fre theu "thought he would doctor it himself," and piocured some nettles, with which he produced a number of resiclez, which 
caused metastasis of the pain from the knee (as he thought) to the ankle; after this, ulceration commenced in both legs. He received no advice during the winter, except from quacks, who treated him for the ulcers, in rain. When I saw him he was much emaciated, almost unable to walk with a staff, and labouring under a severe attack of indigestion, brought on by his long confinement. The nervous irritability was exceedingly sreat, in consequence of the severe pain which he sulfered, and the want of rest. I ordered cataplasms to the ulcers, and gave lim aperients with bitters and anodyne. After the cataplasms had been used for a fow days, the ulcers were dressed with the Cng. acet plumb. Under the above treatment the alcers healed, and the digestive organs considerably improved. At about the beginning of July, I gave him the following $\mathrm{R}$ Hydriod. Iiali. Sss. Infus. Gent. co Jviij. MI. Ft. Mist. St. coch. ij. amp. ter die. After using the above for a few days, he was seized with symptoms of ferer, which I subdued with diaphoretics and aperients. Considering the digestive functions to be not perfectly restored, I again gave him aperients, with bitter infusions, which $I$ continued up to the 15 th of August, when I ordered him the hydriodate, according to the following formula:- $\mathrm{R}$ Hydriod. Kali. Dij. Aq. pura. 3 rij. Syrup pap. a!b. 5ij. M. Ft. II ist. St. coch. ii. amp. ter die. When he commenced the above his nocturnal pains wereworse; the node was larger ; the swelling of the ankle had much increased, and one ulcer had again appeared on the right leg. He has taken the hydriodate since the above mentioned period, with the most decided benefit. After using two bottles of the above mixture (that is, Jiv of hydriodate) lie became free from pain, could sleep well, and his health was much improved. The node has entirely disappeared; the swelling of the arkle is almost gone; he walks well without a staff (which he had not done for 12 months previous); and he is, seemingly, quite well, and I hare not the least doubt but that he will in a few weeks be again able to resume his laborious occupation.

\section{ALBUMEN IN URINE AS A SIGN OF DISEASE.}

A Thesis by MC. Desir of Paris, lately published in the Archives (rínérul de Médecine, contains some interesting facts on the above subject. The theses of $\mathrm{M}$. Desir is one of the best of those which have been presented this year to the Faculty of Medicine. It contains a complete historical record of the question. Of the researches of the authox, we car only give a summary of the results. It presents a great number of experiments, which that gentleman performed in order to determine those diseases which may be identified by the presence of albuminous urine, conducted with much care, upon indivituals labouring under acute or chronic diseases. The propositions deduced by the author are principally the following:-

1st. Cases in which the urine contains a substance that is coagulable by heat, or by nitric acid, must be considered as " albuminous."

2d. When the urine is albuminous, there will always be found an organic or functional lesion of the urinary apparatus.

3d. The urine is not albuminous during a course of mercury, far less during an intercurrent disease of the urinary organs.

4th. In an acute disease the urine may contain a certain quantity of albumen for several days, and sometimes this phenomenon indicates a sanguineous congestion of the kidneys, of the ureters, or of the urinary bladder.

5th. In a healthy person the urine may accidently be albrminous for 24 hours together, towards the termination of an excitement of the urinary passages.

6th. When the urine contains much mucus which is albuminous, if, at the same time, there be present pan along the course of the traject of the ureters, or in the region of the kidneys, these symptoms ought to be attributed to acute inflammation of the mucous membrane of the infundibula, the pelvis venum, or the arteries, and not to an inflammation of the substance of the kidneys.

7th. The urine is alkaline in certain nerhitic affections.

8th. Habitual discharges of albuminous urine, loarled with colouring matter of the blood, is one of the principal symptoms of cancer, or of fungons tumours of the urinary organs.

PROPOSAL TO EXAMINE STUDENTS AT 'THE LECTTRE - ROOMS BEFORE ENTRANCE TO THE COCRSES.

\section{To the Editor of The LANCET.}

SIR:-The intellectual, and even the moral, condition of but too large a portion of medical students is considered by many (and perhaps not without reason) to be very inferior to that which belongs to the position thes ought to occupy in society. I admit. that the more strict examinations at Apothe. caries' Hall, and the College of Surgeons, which have been introluced of late, are conducire to the improrement of the mental and moral state of the medical students, inasmuch as they rencler it incumbent on the candidate for medical honours to possess a better knowledge of every branch of his profession. But is it not desirable, that, in addition to the necessity of obtaining a di- 